\title{
Populações Ribeirinhas e Exército: conflito de propriedade e direitos fundamentais em tensão na Amazônia Brasileira - solução à luz do princípio da ponderação
}

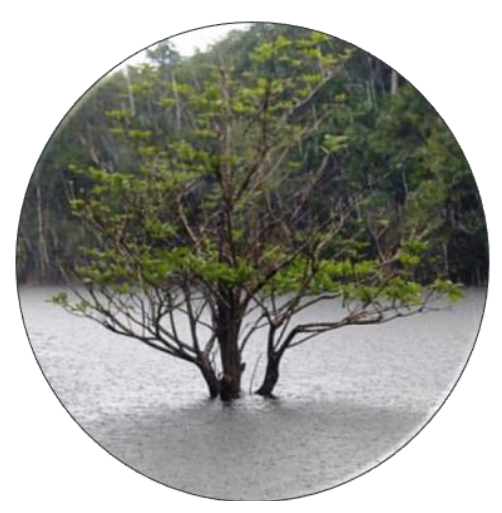

Therezinha J.Pinto Fraxe ${ }^{1}$

Rosane M. Brum Vargas ${ }^{2}$

\section{Resumo}

O conflito territorial existente entre comunidades tradicionais e Exercito Brasileiro, localizado no campo de instrução do CIGS em Manaus, arrasta-se há mais de três décadas e tem dupla afetação: de um lado os interesses das comunidades em permanecer e ter a titularidade da terra, de outro a soberania e interesses da União, entremeados à preservação do meio ambiente. As terras, antes, do Governo do Estado do Amazonas, já possuíam famílias tradicionais ali residindo, foram doadas à União na década de 60, e após, destinadas a campo de instrução do Exército. A iniciativa de composição na solução do conflito partiu do Comando da $12^{\mathrm{a}}$ Região Militar sediada em Manaus (AM). Colisão entre direitos fundamentais. Aplicação do princípio da ponderação no equilíbrio de interesses.

Palavras-chaves: Exército Brasileiro, populações ribeirinhas, princípio da ponderação, territorialidade.

\begin{abstract}
The territorial conflict between traditional communities and the Brazilian Army, located in the field of education of CIGS in Manaus, dragged on for more than three decades and has double affectation: on one hand the interests of the communities to remain and take ownership of land, sovereignty and other interests of the Union, intermingled with the preservation of the environment. The land before, the Government of the State of Amazonas, already had traditional
\end{abstract}

1 Doutora em Sociologia Ambiental/UFC/CE.; Diretora do Centro de Ciências Ambientais/UFAM. Engenheira Agrônoma, Professora Titular do Departamento de Agronomia da UFAM/AM. Email: tecafraxe@uol.com.br.

2 Mestranda em Ciências Ambientais e Sustentabilidade da Amazônia (CCA/UFAM), Advogada (Direito Socioambiental), Licenciatura em Matemática e Bolsista CNPq. Email: rosanebv.adv@gmail.com. 
families residing there, were donated to the Union in the 60 s and after the intended field of education the Brazilian Army. The initiative composition in the solution of the conflict came from the 12th Military Region Command headquartered in Manaus (AM). Collision between fundamental rights application of the principle of balancing the balance of interests.

Keywords: Brazilian Army, population riverine, principle of weighting, territoriality.

\section{Introdução}

Os Direitos fundamentais em tensão no caso das comunidades existentes dentro do campo de instrução do exército brasileiro - CIGS, na área do Puraquequara, proximidades da cidade de Manaus, se revelam um problema típico de dupla afetação, a se encontrar a incompatibilidade de vigência de direitos relativos ao meio ambiente, territorialidade de povos tradicionais e defesa nacional.

Identidades coletivas diferenciadas emergem no Brasil, revelando nas ultimas décadas e existência de diversos grupos étnicos, organizados em movimentos sociais, que buscam garantir e reivindicar direitos, que lhe foram negados pelo estado. Novos atores sociais surgem destas demandas, como bem afirma Wolkmer:

O novo sujeito histórico coletivo, articula-se nas exigências de dignidade, de participação, de satisfação mais justa e igualitária das necessidades humanas fundamentais de grandes parcelas sociais excluídas, dominadas e exploradas das sociedades. (WOLKMER, 2005)

Este artigo tem por finalidade tentar elucidar o caso concreto do conflito quanto a propriedade das terras, existente entre povos tradicionais e o Exercito Brasileiro. Nessa situação para se evitar o completo esvaziamento da tutela ao meio ambiente na região, impõe-se a relativização dos respectivos bens jurídicos até o limite da preservação do núcleo essencial de cada direito fundamental confrontado.

Nesse sentido, antes de tentar resolver questões fundiárias ou outras na Amazônia é preciso refletir nos ensinamentos de Witkoski,em que: 
tentar compreender homens e mulheres, as terras, as florestas e as águas de trabalho no interior do Amazonas é buscar o desvendamento da realidade. Porém, é necessário cautela, pois a realidade não pode ser compreendida apenas desvendando-se o dia a dia, mas numa dimensão em que este se inclui na totalidade. Esse dia-a-dia tem que ser compreendido no contexto em que o espaço Amazônico é produzido, não sendo apenas a soma mecânica de atividades diversas, mas a totalidade que os engloba. (2010, p.19).

Neste caso, as autoridades competentes e atores interessados, que participaram e ainda participam da análise do caso, tais como Ministério Publico Federal (MPF), Secretaria de Patrimônio da União (SPU) Procuradoria da República no Amazonas (PGE), Advocacia Geral da União (AGU), Centro de instrução de Guerra na Selva (CIGS), Comando da $12^{\mathrm{a}}$ Região Militar, representantes das comunidades. Buscaram uma solução harmônica aos interesses através do principio da ponderação, da equidade, necessidade e justiça social. Principio da ponderação, este, somente possível à luz do caso concreto, fundado em particularidades especiais de concerto, razão pela qual foi buscado os esforços de hermenêutica neste estudo de caso de colisão de princípios, de direitos coletivos e de minorias, em especial na Amazônia.

A iniciativa de composição na solução do conflito partiu do Comando da $12^{\mathrm{a}}$ Região, implementando diversas atividades de preparo, tais como reconhecimentos especializados, levantamentos topográficos, cadastramento das famílias, realização de audiências publicas, etc., com o objetivo de resolver problemas sociais e patrimoniais das comunidades tradicionais ribeirinhas residentes em terras da União, sob a responsabilidade do Exército Brasileiro.

A seguir trechos do Relatório emitido pela Seção de Patrimônio e meio Ambiente da $12^{\text {a }}$ Região Militar:

Urgia a necessidade de regularização das áreas utilizadas pelas Comunidades. Assim, foram promovidas várias reuniões e assembleias de conciliação, entre o Comando do Exército representado pelo Comando da $12^{\mathrm{a}} \mathrm{RM}, \mathrm{MPF}, \mathrm{AGU}$ e representantes das Comunidades, no sentido de encontrar uma solução para o problema. (2013)

$\mathrm{Na}$ tentativa de esclarecer o conflito e sua composição é que passamos a expor a localização geográfica e temporal, os modos de vida das comunidades, 
origem do conflito, mazelas deixada pelo Estado, em franca desconsideração aos entes coletivos e aos direitos fundamentais. A visibilidade social e o reconhecimento de direitos destes grupos decorrentes da articulação dos mesmos, tem gerado novos paradigmas no campo jurídico. Paradigmas, até então, desconhecidos, normas pouco reconhecidas ou ignoradas por tratarem de "povos originários".

As propostas e a solução à luz do principio da ponderação, onde as eventuais incompatibilidades serão dirimidas frente a um modo de interpretação que mantenha íntegro o núcleo essencial de cada um dos direitos fundamentais sobrepostos.

\section{Populações tradicionais}

Para entendermos melhor a categoria das "comunidades ribeirinhas" envolvidas no conflito, faz-se necessário um breve estudo da acepção do termo, na visão dos cientistas sociais e ambientais.

Partimos do pressuposto de que o conceito de "populações tradicionais", desenvolvido pelas ciências sociais e incorporado ao ordenamento jurídico, somente pode ser compreendido com base na interface entre biodiversidade e sociodiversidade (SANTILLI, 2005, p. 124).

Segundo Santilli (2005), a categoria "populações tradicionais" já é relativamente bem aceita e definida entre os cientistas sociais e ambientais.

Para Léna (2002, p. 18) existem outras dificuldades para a categoria "populações tradicionais":

A categoria "populações tradicionais" formada por vários grupos humanos (quilombolas, ribeirinhos, jangadeiros, sertanejos, indígenas, etc.) constituem ambiguidades, pois misturam categorias nativas, sociológicas e políticas. Essas ambiguidades dificultam a definição de políticas adaptadas. Sendo assim, certas populações parecem ter um estatuto bem definido hoje, como é o caso das populações indígenas, dos seringueiros e dos quilombolas, outras nem tanto, como é o caso dos ribeirinhos. São construções elaboradas para fins jurídicos. 
Neste trabalho consideraremos os termos: populações tradicionais, sociedades tradicionais, comunidades tradicionais, ou ainda, comunidades (populações) ribeirinhas, como possuidores de uma mesma conotação.

Assim sendo, utiliza-se neste estudo a noção de "comunidades tradicionais" para definir grupos humanos diferenciados sob o ponto de vista cultural, que reproduzem historicamente seu modo de vida, de forma mais ou menos isolada, com base na cooperação social e relações próprias com a natureza. Essa noção refere-se tanto a povos indígenas quanto a segmentos da população nacional, que desenvolveram modos particulares de existência, adaptados a nichos ecológicos específicos (DIEGUES; ARRUDA, 2001, p. 27).

Algumas vezes, também será utilizado o termo "camponês amazônico", que segundo Witikoski (2010), a utilização da categoria camponês é adequada e se aplica à produção familiar existente na várzea amazônica.

A Lei da Mata Atlântica (Lei 11428/2006) também conceitua população tradicional, como "população vivendo em estreita relação com o ambiente natural, dependendo de seus recursos naturais para a sua reprodução sociocultural, por meio de atividades de baixo impacto ambiental".

\section{0 conflito e a territorialidade}

A posse das terras dos ribeirinhos que vivem dentro espaço delimitado como "campo de instrução do Cigs", na ótica legal dominante, é apenas posse de fato, dado que essas terras são propriedade da União. Mas isso não impede que eles vivam, trabalhem e se reproduzam socialmente, e sintam como se o espaço realmente seja seu, o seu território.

Nas palavras de Therezinha P. Fraxe (2011) "Por esta razão, a percepção do espaço é aqui, basicamente relatada pelos próprios camponeses, que moram. Sentem e vivem o lugar. Devo lembrar que concebo o espaço como liberdade e o lugar como segurança, da mesma forma como o concebe Yi-Fu Tuan (1980 e 1983)" 
Relativo à posse de terras, a migração na Amazônia se aprofundou nos anos 70, devido a grandes programas de colonização e da construção da Transamazônica, em tempos da ditadura no Brasil. Na década de 70, a Amazônia já povoada por tribos indígenas, quilombos, grupos de seringueiros e população ribeirinha que pescavam e plantavam por subsistência. Esses grupos começaram a perder as suas terras com o início da regularização fundiária proposta pelo governo. Porém, a Constituição Federal dá prioridade de posse sobre as terras às comunidades tradicionais.

Amparados pelo decreto federal 6.040 de fevereiro de 2007, os povos e comunidades tradicionais se reconhecem culturalmente diferenciados, que possuem formas próprias de organização social. Além disso, eles ocupam e usam territórios e recursos naturais como condição para sua reprodução cultural, social, religiosa, ancestral e econômica, utilizando conhecimentos, inovações e práticas gerados e transmitidos pela tradição.

\footnotetext{
Art. 3o Para os fins deste Decreto e do seu Anexo compreende-se por:

I- Povos e Comunidades Tradicionais: grupos culturalmente diferenciados e que se reconhecem como tais, que possuem formas próprias de organização social, que ocupam e usam territórios e recursos naturais como condição para sua reprodução cultural, social, religiosa, ancestral e econômica, utilizando conhecimentos, inovações e práticas gerados e transmitidos pela tradição;

II - Territórios Tradicionais: os espaços necessários a reprodução cultural, social e econômica dos povos e comunidades tradicionais, sejam eles utilizados de forma permanente ou temporária, observado, no que diz respeito aos povos indígenas e quilombolas, respectivamente, o que dispõem os arts. 231 da Constituição e e $\underline{68 \text { do }}$ Ato das Disposições Constitucionais Transitórias e demais regulamentações; (Dec. 6.040 de fevereiro de 2007).
}

O problema teve sua origem na década de 60, quando o Governo do estado do Amazonas, com a lei no 672, de 21 de novembro de 1967, doou à União, as terras situadas na região do Puraquequara, com destinação especifica para o funcionamento de área de instrução do CIGS, com confrontações e limites devidamente definidos. Sendo que a Lei no 939 de 08 de julho de 1970 ampliou a área com a doação de terras devolutas situadas ao longo da margem direita da estrada do Puraquequara, também com limites definidos. 


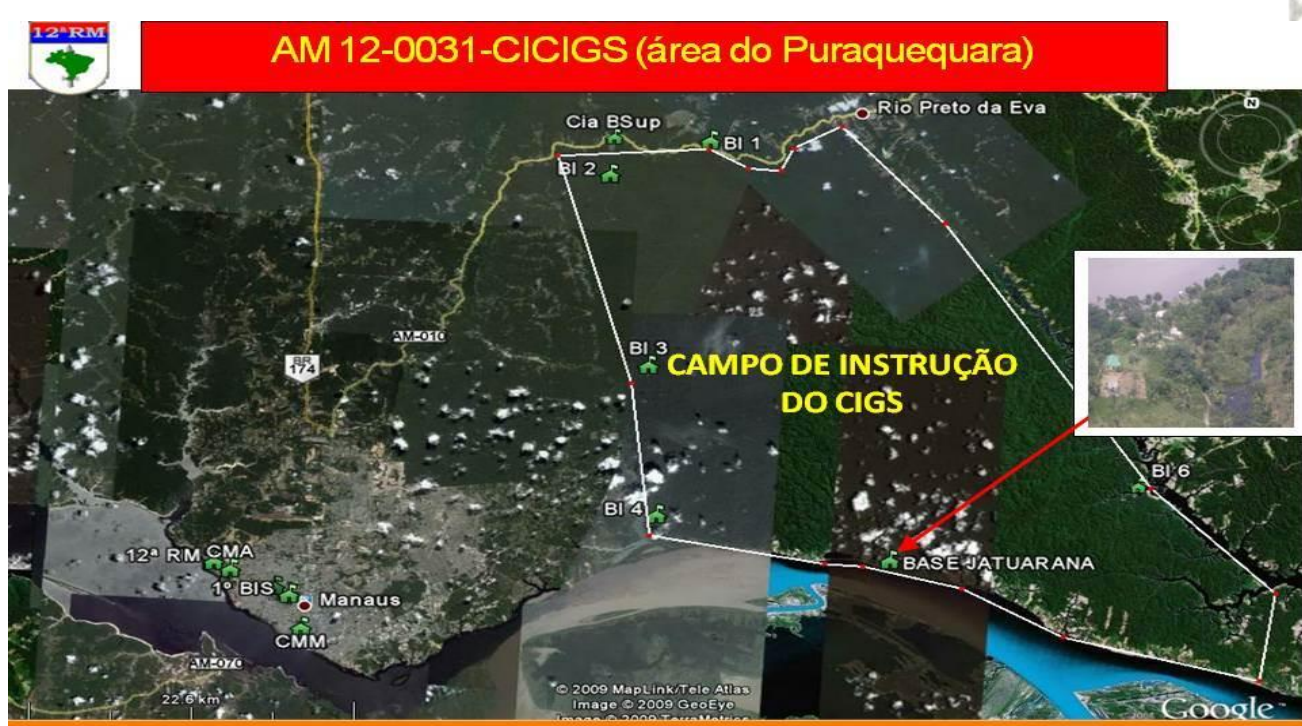

Fonte: $12^{\mathrm{a}}$ Região Militar/Exerc.Bras. - 2012

As áreas estão registradas nos Cartórios de Registro de imóveis dos municípios de Rio Preto da Eva sob o n 388 e no $4^{\circ}$ Cartório de Manaus sob o $\mathrm{n}^{\mathrm{o}} 10.217$.

Restando esta área total sob a Jurisdição do Exército Brasileiro, isto é, sob a administração do Exercito brasileiro, sendo classificada como área de interesse da segurança - defesa nacional e com proteção específica, prevista na Constituição Federal e nas diretrizes de defesa nacional.

Ocorre que o Governo Do Amazonas ao doar as terras para a União e esta instalar bases do Exercito, ignorou a população tradicional, que lá já vivia há mais de 50 anos, e ainda vive até hoje de atividades de economia extrativista, lavoura de subsistência e pesca artesanal, sendo que alguns ainda possuem título da terra com mais de $100(\mathrm{cem})$ anos.

Nesse contexto se faz necessário questionar, como se dá o envolvimento do camponês amazônico com seu território (extensão de terra, floresta e água), que pode pertencer de direito ou de fato à ele e sua família. Antonio Carlos WITKOSKI, responde essa questão: 
"A primeira característica desse território é que ele possui e não possui fronteiras. Quando se trata de atividades agrícolas, o "território" camponês pode ser reduzido à sua propriedade - a várzea baixa e $\backslash$ ou alta e, as vezes um pedaço de terra, no ambiente de terra firme. Quando se trata das atividades desenvolvidas na floresta de terra firme, pelo fato da floresta não possuir fronteiras demarcada, o camponês amazônico transforma-se num trabalhador nômade. Quando se trata de águas de trabalho, a plasticidade do território fica condicionada ao ambiente "aquático público" (rios) e aos "aquáticos coletivos" (os lagos). (2011)

Isso acontece assim porque a noção de território que as populações tradicionais (camponeses) possuem com relação à natureza, possui singularidades.

O Governo do amazonas na ocasião das doações se comprometeu em realocar os moradores destas terras ou indeniza-los de acordo com seus títulos e ou posses. Mas o que se conseguiu apurar é que apenas poucos proprietários, melhor orientados, na década de 80, impetraram ação na justiça contra o Estado do Amazonas e foram indenizados - pois a justiça concluiu que houve apropriação indireta em benefício da União. o restante permaneceu até o final do séc. passado no mais completo esquecimento nas políticas do Estado.

Verifica-se que nos ultimas décadas a única presença do Estado ali existente, tem sido as Forças Armadas, que auxiliam na preservação do meio ambiente, na segurança dos ribeirinhos e prestando-lhes apoio de saúde em ACISOS (ações cívicos sociais).

Ocorre que as comunidades foram aumentando, as famílias proliferando cada vez mais, onde antes existia o pai a mãe e três ou quatro filhos, hoje já acrescidas de nora, genros, netos, compõem 190 famílias (aproximadamente 800 pessoas). Aumentando assim as construções de moradias, expansão das roças, da pesca e extrativismo, levando as comunidades além dos limites estabelecidos pela SPU (secretaria de patrimônio da União).

Nesse ínterim, com a proximidade da zona urbana, surge com frequência especuladores da área, pescadores que utilizam a pesca para fins comerciais, atitudes essas de pessoas estranhas às comunidades. Todos esses 
acontecimentos ensejando uma postura mais rigorosa do Exercito (CIGS) na localidade.

O conflito de interesses entre os moradores de comunidades e o Comando Militar da Amazônia ficou mais evidente e se tornou público em 2009, com diversas reportagens na mídia local. Tendo ao fundo a Pastoral da terra com ideologias contrarias à concessão da CDRU, se posicionando frontalmente, a estimular o desentendimento do Ribeirinhos com o Exército e outros atores sociais aproveitando-se da situação para legitimar outros interesses diversos, que não os dos Ribeirinhos. (Relatório 12a RM- 2013)

As comunidades protestaram e com a repercussão na imprensa o caso foi para no Ministério Publico Federal, na Assembléia Legislativa e no ITEAM (instituto de Terras do Amazonas). O ITEAM entrou no diálogo e propôs que a melhor forma de regularização fundiária dos moradores seria a Concessão de Direito Real de Uso (CDRU) - em declaração publicada no site do ITEAM (Instituto de Terras do Estado do Amazonas).

A negociação entre as comunidades e Exercito Brasileiro vem sendo acompanhada ao longo destes quatro últimos anos pela Advocacia Geral da União (AGU), Ministério Público Federal (MPF) e Procuradoria da República do Amazonas (PGA)

O território onde o ribeirinho vive, a terra, a floresta e a água participam de modo decisivo da forma como eles vivem, como "procuram dar plenitude à vida". Pode ser definido como uma porção da natureza que lhes fornece e garante os meios de subsistência, de trabalho e produção, os meios de produzir as relações sociais (Godelier (1984, p83). O ribeirinho vive em perfeita harmonia com a natureza do seu entorno, dela fazendo parte, como um todo.

\section{A localização e Identificação das Comunidades}

O conflito centra-se especificamente nas áreas de treinamento do CIGS, após a Vila Puraquequara (zona leste de Manaus), ao longo das margens do Rio 
Amazonas, numa extensão de $40 \mathrm{~km}$, Beiradão do Rio Amazonas, zona rural do Município de Manaus e no afluente do Rio Preto da Eva - igarapé do Tiririca.

$\mathrm{Na}$ área do CIGS, delimitada, conforme escrituras antes citadas, localizam-se as cinco comunidades, situando-se as quatro primeiras no Beiradão do Rio Amazonas e a ultima no afluente do Rio Preto da Eva, assim identificadas em ordem de chegada, saindo da cidade de Manaus:

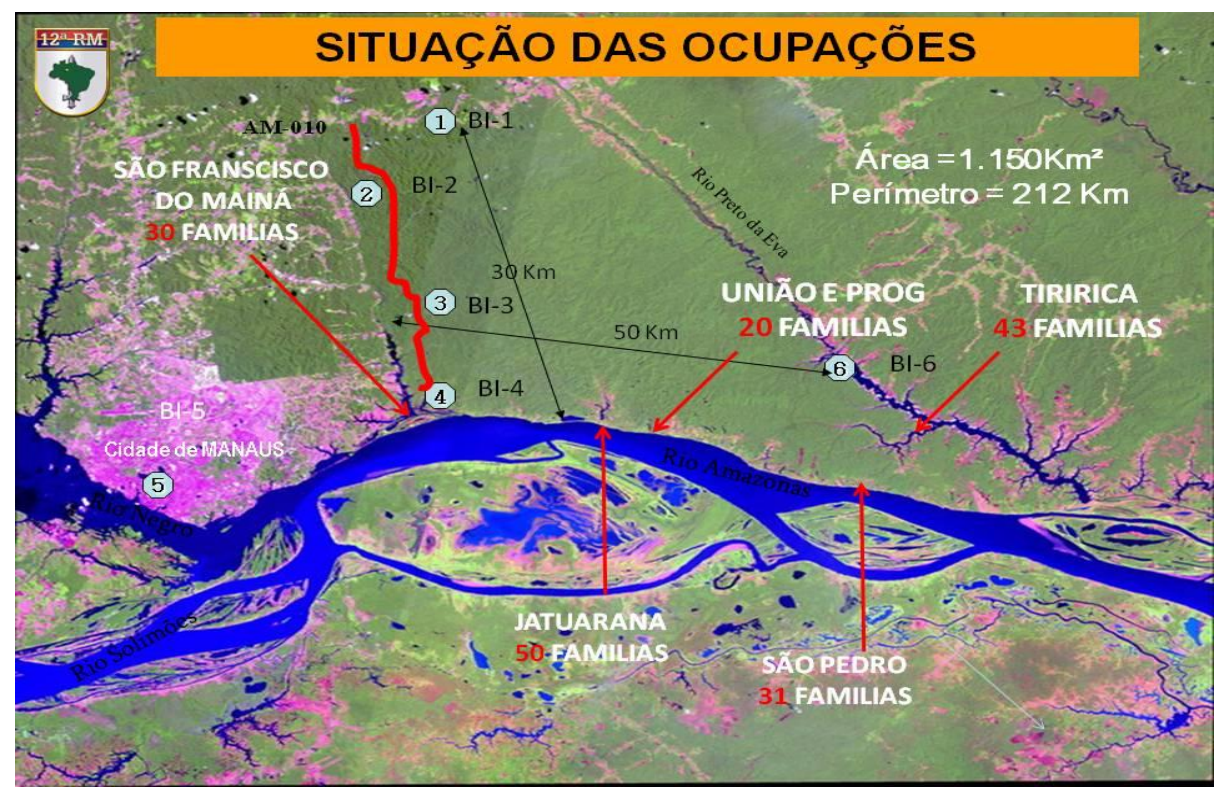

Mapa 1 - São Francisco do Mainá, Jatuarana, União e Progresso ou São Lázaro, São Pedro da Costa do Tabocal; - São Francisco do Tiririca.

Fonte: $12^{\mathrm{a}} \mathrm{RM} /$ Exército Brasileiro- 2012

\section{O modo de vida das comunidades e a Sustentabilidade}

Os ribeirinhos, seres humanos instalados às margens dos rios, desenvolvem permanentemente uma estreita relação com o ambiente, a qual se manifesta numa intensa interação. Isso pode ser revelado em diversos aspectos do cotidiano em relação à conservação do solo, da água, da fauna e da flora que caracterizam a condição sociocultural das comunidades tradicionais. O fato de ocupar as margens dos rios Amazonas e Solimões possibilitou-lhes adaptações às condições ecológicas existentes. Nesse sentido, de acordo com Tuan (1980), 
uma estreita relação inclui os laços afetivos dos seres humanos com o meio ambiente.

As comunidades destas localidades, em geral, no que tange às atividades geradoras de renda, vivem da agricultura de subsistência, pesca artesanal, extrativismo vegetal e eventualmente caça e o exercício esporádico de turismo. Uma parcela bem pequena possui emprego público.

Segundo relatório do Ministério Publico federal, observa-se que A Comunidade do Mainá fica em meio a grande área de floresta conservada, à

direita do lago do Mainazinho, rico em pesca e que seu entorno é bem conservado, com presença de floresta densa. As demais comunidades se apresentam visivelmente mais devastadas, devido á grandes áreas desflorestadas (por particulares) da pecuária. ( Procedim. Administrativo do MPF n²004$29 \backslash 2010)$.

As comunidades ribeirinhas que habitam os campos de instrução do CIGS, são reconhecidas pelas características atribuídas por Diegues (1996) para culturas e sociedades tradicionais, apresentando: modo de vida, dependência e até simbiose com a natureza, os ciclos naturais e os recursos naturais renováveis; conhecimento aprofundado da natureza e de seus ciclos que se reflete na elaboração de estratégias de uso e de manejo dos recursos naturais [...]. Nesse contexto melhor define, Fraxe:

Os povos ribeirinhos que habitam a várzea do rio SolimõesAmazonas apresentam características tradicionais em seus sistemas de produção agroflorestal oriundos de práticas indígenas e caboclas de produção. Onde a terra e água se complementam, buscando o equilíbrio da vida. Esse grupo tem as peculiaridades de dependência e simbiose com a natureza, conhecimento tradicional transferido de geração á geração, noção de território ou de espaço, onde o grupo se reproduz econômica e socialmente, moradia e ocupação desse território por várias gerações, o trabalho com a terra é de policultivo de subsistência com técnicas de retroalimentação do solo, etc. FRAXE (2011).

Os exemplos revelados pelas comunidades ribeirinhas no que se refere ao funcionamento de apropriação, uso e gestão dos recursos naturais podem ser 
adotados como referência. As pesquisas têm mostrado que, se o respeito pelo uso sustentado dos recursos tornar-se algo compartilhado pela comunidade aumentam as chances de êxito de formas de gestão capazes de favorecer o alcance simultâneo de uma distribuição mais equitativa da riqueza gerada e de aumento das margens de sustentabilidade dos recursos da comunidade (Diegues, 1994).

O Relatório Brundtland, da Comissão Mundial do Meio Ambiente e Desenvolvimento (CMMAD,1988), o qual foi responsável pelas primeiras conceituações oficiais, formas e sistematização sobre Desenvolvimento Sustentável, define o "Desenvolvimento Sustentável como desenvolvimento que satisfaz as necessidades do presente sem comprometer a capacidade das futuras gerações de satisfazerem as suas próprias necessidades".

A sustentabilidade ambiental, principalmente de comunidades ribeirinhas, desenvolveu-se por meio de comportamentos éticos, nos seus aspectos culturais, mantendo uma preocupação na conservação e preservação da vida e do ambiente.

A sustentabilidade é um processo que implica em um ajuste social e econômico com métodos e técnicas, para que a natureza atenda às necessidades básicas da comunidade.

As comunidades ribeirinhas caracterizam-se pela diversidade de suas atividades produtivas, atributo que assegura sua sobrevivência, contanto que essa diversidade produtiva esteja relacionada com o padrão de necessidades e recursos disponíveis no local.

Sachs (1980) afirma que "trata-se de buscar soluções locais aos problemas globais, valorizando do melhor modo possível as potencialidades de cada ecossistema, os recursos específicos do mesmo e as contribuições de cada cultura"

Portanto, são consideradas populações tradicionais aquelas comunidades que dependem culturalmente do extrativismo dos recursos naturais e que ocupam ou utilizam-se de uma mesma área geográfica há várias gerações, de forma tal que 
não provocam alterações no meio ambiente, isto é, são partícipes da natureza. Essas comunidades são consideradas, pelas suas peculiaridades sociais e culturais, como capazes de transmitir saberes e vivências no uso de recursos naturais, baseado no conhecimento acumulado e à permanente relação com a natureza.

O estudos destas comunidades revelam a multiplicidade de dimensões da sustentabilidade ambiental, que é dada pela complexidade natural, evidenciando a inter-relação dos seus componentes: estrutura social (a comunidade e as gerações), instrumentos sociais (as escolas e as associações), biodiversidade (uso, patrimônio, conservação e importância).

Acredita-se que a sustentabilidade ambiental é a responsável pela manutenção das comunidades ribeirinhas. Assim como o seu modo de vida, as estratégias utilizadas no uso adequado e, consequentemente, na conservação dos recursos naturais, como a caça e coleta de alimentos, a pesca, a lavoura, a criação de animais e as alternativas para a conservação.

As comunidades ribeirinhas, num relacionamento harmônico e com a colaboração do Exército (militares do Cigs), desempenham fundamental papel na conservação da biodiversidade do território em questão, principalmente se forem consideradas as constantes alterações decorrentes da ação de grupos econômicos, grileiros, madeireiros, fazendeiros, industriais e mesmo do próprio turismo no entorno.

Percebe-se que nessas comunidades, o seu conhecimento tradicional, o comportamento ético com a natureza e com o apoio do exército na proteção do meio ambiente, evitando a invasão de exploradores (madeireiros, grileiros, pescadores profissionais, etc.), desempenham importante papel na conservação da biodiversidade local. É visível no seu entorno a preservação ambiental com um mínimo de degradação.

Alcançar a sustentabilidade ambiental requer a integração de esforços em diversos setores e uma troca radical de condutas e estilos de vida, incluindo padrões de produção e consumo. 
A seguir a imagem da Comunidade São Francisco do Mainá em época de cheia, ás margens do Lago do Puraquequara / Rio Amazonas

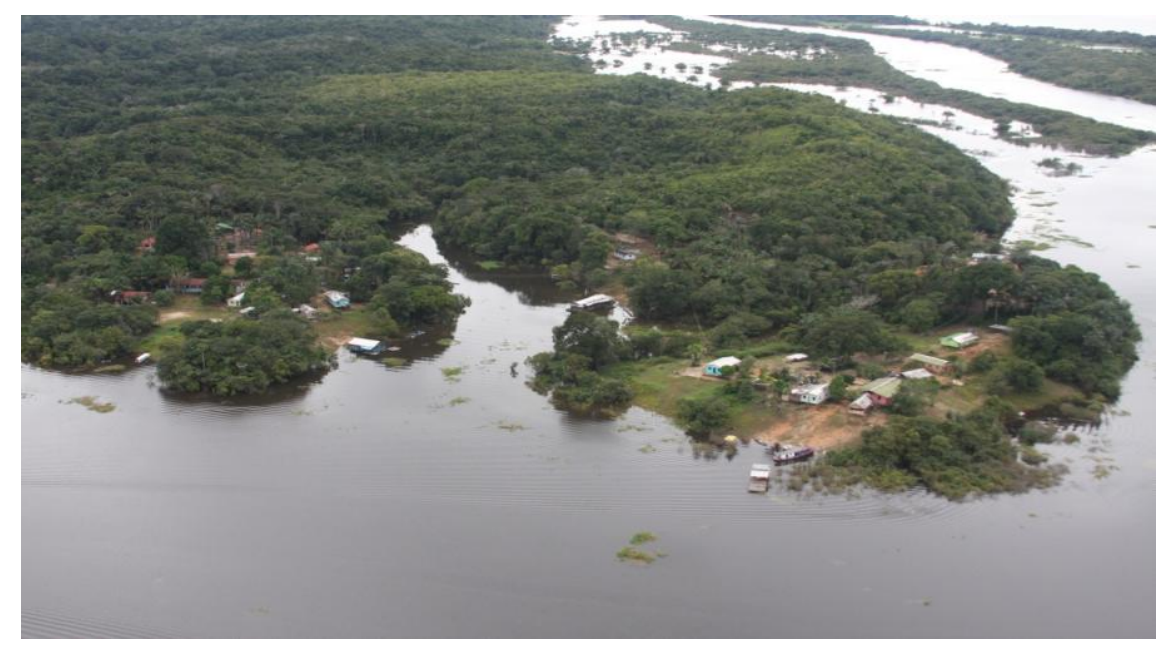

Figura 1 - Lago do Puraquequara / Rio Amazonas

Fonte: 12aRM- Exercito. Brasil. - 2012

\section{Dos direitos fundamentais em Tensão e o principio da Ponderação}

\subsection{Os direitos fundamentais}

Neste estudo busca-se analisar a colisão dos direitos fundamentais na perspectiva do Supremo Tribunal Federal, dessa forma é imprescindível determinar o que vem a ser direitos fundamentais. Tal tarefa é difícil pois existe uma vasta terminologia para o tema, até mesmo na própria Constituição Federal de 1988, vejamos: direitos humanos, direitos e garantia fundamentais, direitos e liberdades constitucionais e direitos e garantias individuais.

Alexy apud Carvalho (2009, p. 16) entende por direitos fundamentais aqueles constitucionalmente válidos.

Importante se ressaltar que os direitos fundamentais não constituem apenas aqueles que se encontram no texto da Carta Política, mas também os que não foram expressamente previstos, que implicitamente podem ser deduzidos. 
Tendo em vista a existência de direitos apenas materialmente fundamentais e não formal e materialmente fundamentais, considerando os ensinamentos de Carvalho (2009, p. 16).

Dentro do tema direitos fundamentais, comumente se discute a diferença entre direitos humanos e direitos fundamentais. Ingo Wolfgang Sarlet (2006, p. 35 e 36) confere ao aspecto espacial da norma o primeiro fator preponderante de distinção:

o termo 'direitos fundamentais' se aplica para aqueles direitos do ser humano, reconhecidos e positivados na esfera do direito constitucional positivo de determinado Estado, ao passo que a expressão 'direitos humanos' guardaria relação com os documentos de direito internacional.

Uma das principais características dos direitos fundamentais, enquanto princípios que são, é a sua relatividade, ou seja, por se tratarem de princípios constitucionalmente previstos, os direitos fundamentais não se revestem de caráter absoluto, em caso de tensão entre eles cabe o sopesamento de um sobre o outro para que se decida daquele mais adequado.

No exemplo citado, por não existirem princípios superiores a outros, apenas a análise do caso concreto é que decidirá o mais adequadamente aplicado. Marmelstein (2008, p. 368) afirma que o STF, assinalando a possibilidade de limitação dos direitos fundamentais, decidiu que não há, no sistema constitucional brasileiro, direitos ou garantias que se revistam de caráter absoluto. O STF tem tratado questões dos povos e comunidades tradicionais, recentemente caso de demarcação da terra indígena Raposa Serra do Sol (Roraima) e análise da constitucionalidade do decreto de reconhecimento dos remanescentes de quilombos (Decreto 4.887 de 2003 - ADIN 3239).

Para Alexandre de Morais (2003, p. 61), "os direitos e garantias fundamentais consagrados pela Constituição Federal não são ilimitados, uma vez que encontram seus limites nos demais direitos igualmente consagrados pela carta Magna (princípio da relatividade)". 
No caso em questão, semelhante aos casos emblemáticos "da terra indígena Raposa Serra do Sol" (em Roraima) e o da "base aérea de Alcântara" (no Maranhão), bem representa a colisão entre direitos fundamentais entre interesses territoriais das comunidades tradicionais de um lado e exército brasileiro de outro.

Com o aumento populacional dentro destas áreas, o Exercito começou a restringir o acesso a maiores trechos de lagos e floresta, justificando como medidas de segurança aos moradores, estes por sua vez, passaram a se queixar destas situações. E a se mobilizarem em reuniões e denuncias, de que não tinham livre acesso e uso de suas terras.

Momentos estes em que começaram a tomar conhecimento de que na realidade não tinham titularidade alguma do terreno, e as que existiam já estavam há muito caducas pelo decurso do tempo e obra do Estado do Amazonas, quando doou as terras para a União com finalidade de instalação do CIGS no local.

Surgiu desta forma nas populações locais, a insegurança inicial em descobrir que não tinham qualquer garantia legal de que a terra em que nasceram, viveram e trabalhavam ate o momento eram suas, e de que podiam dispô-las como bem entendessem. Aparece assim, a necessidade de verem reconhecido de alguma forma, pela proteção estatal, a sua titularidade e a delimitação fundiária.

Por outro lado, de acordo com a manifestação do CMA (comando Militar da Amazônia) em resposta a PGA, ofício n 57 -DU- S3, as necessidades, interesses e funções do Exército em evitar a invasão de novo moradores, impedir o desmatamento, preservar a flora e a fauna, e manter em atividade efetiva e permanente treino de forças estratégicas de defesa Nacional, necessitando da área do CIGS. Desta forma á área do CIGS atende às Diretrizes de Política de Defesa Nacional e Goza de proteção legal específica, e dada à importância estratégica e da riqueza que abriga, a Amazônia Brasileira é considerada área prioritária. Assim o Exército, também cumpre comandos constitucionais, e as 
terras do conflito são bens públicos da União com destinação específica, além da preservação ambiental.

Com a evidencia e dimensão do conflito, da colisão dos direitos, passaram a dialogar entes estatais e Federais, tais como ITEAM, PRA, MPF, Exército, comunidades, CPT, na busca de uma solução pacifica e proveitosa para ambos os lados, vez que estavam em colisão direta diversos princípios norteadores de nossa Constituição Federal.

Diante da visão dos renomados autores, conclui-se que o caráter de relatividade do qual são revestidos os princípios torna possível que, em caso de choque entre eles, haja a ponderação entre eles e decida-se pela aplicação do principio mais adequado ao caso concreto.

Considerar os direitos fundamentais como princípios significa, portanto, aceitar que não há direitos com caráter absoluto, já que eles são passíveis de restrições recíprocas. O Brasil é signatário de documentos internacionais em direitos humanos que podem assumir natureza constitucional ou supra-legal de proteção às comunidades tradicionais.

\subsection{Princípio da ponderação}

O novo século iniciou-se fundado na percepção de que o Direito é um sistema aberto de valores. O constitucionalismo moderno promoveu uma volta aos valores, uma reaproximação entre ética e Direito. No entanto a novidade das últimas décadas está no reconhecimento pela ordem jurídica da existência de princípios.

Os princípios constitucionais passaram a ser a síntese dos valores abrigados no ordenamento jurídico. Eles espelham a ideologia da sociedade, seus postulados básicos, seus fins. Os princípios dão unidade e harmonia ao sistema, integrando suas diferentes partes e atenuando tensões normativas.

Os direitos e garantias fundamentais, cuja proteção foi destacada pelo Constituinte de 1988, têm as mesmas características dos princípios, na medida em 
que atuam como uma forma de concretização do princípio da dignidade da pessoa humana.

$\mathrm{Na}$ colisão dos direitos fundamentais utilizar-se-á da aplicação do princípio constitucional fundamental da proporcionalidade, que concederá uma aplicação coerente e segura da norma constitucional, através de juízos comparativos de ponderação dos interesses envolvidos no caso concreto.

Considera-se existir uma colisão autêntica de direitos fundamentais, conflito de direitos, quando o exercício de um direito fundamental por parte do seu titular colidir com o exercício do direito fundamental por parte de outro titular.

De acordo com o princípio acima, delineado como princípio da concordância prática, os direitos fundamentais e valores constitucionais, deverão ser harmonizados por meio de juízo de ponderação que visa preservar e concretizar ao máximo os direitos e bens constitucionalmente protegidos, mediante concessões mútuas, se produzir um efeito favorável, mediante o mínimo sacrifício dos princípios contrapostos, buscando o bem-estar social, com fundamentos na dignidade do ser humano.

Válida é a leitura das premissas de Robert Alexy:

Ocorre que, em uma ordem pluralista, existem outros princípios que abrigam decisões, valores ou fundamentos diversos, por vezes contrapostos. A colisão de princípios, portanto, não é só possível, como faz parte da lógica do sistema, que é dialético. Por isso a sua incidência não pode ser posta em termos de tudo ou nada, de validade ou invalidade. Deve-se reconhecer aos princípios uma dimensão de peso ou importância. À vista dos elementos do caso concreto, o intérprete deverá fazer escolhas fundamentadas, quando se defronte com antagonismos inevitáveis, como os que existem entre a liberdade de expressão e o direito de privacidade, a livre iniciativa e a intervenção estatal, o direito de propriedade e a sua função social. A aplicação dos princípios se dá, predominantemente, mediante ponderação.

A ponderação consiste, portanto, em método para se tomar decisões jurídicas nos denominados "casos difíceis" ou "bard cases", nos quais tenha restado insuficiente ou impossibilitado o juízo de subsunção, mormente quando a 
mesma situação ampara a aplicação de normas da mesma hierarquia jurídica, mas que indicam direções completamente opostas. Onde é preciso identificar com clareza o núcleo essencial de cada um dos bens jurídicos protegidos.

Aplicado o principio da ponderação, pois ponderar significa decidir por argumentos válidos, de acordo com normas do estado Brasileiro, chegou-se a conclusão que a melhor forma de regularização fundiária será a CDRU (concessão de direito Real de Uso Resolúvel). Isto é conceder ás famílias ou comunidades residentes dentro das delimitações do campo de Instrução do CIGS, um título legal (a CDRUR) pois esta delimita o terreno de cada um, permite a permanência das famílias em suas terras e o repasse aos seus herdeiros, plantarem áreas previamente demarcadas, caçar e pescar na região, desde que fora do período de treinamento militar, poderão fazer financiamento em bancos, etc. Mas com um elenco de regras de convivência para ambos os lados, que deverão ser respeitadas, principalmente as ambientais. Também proibindo a entrada de novos moradores.

\section{Considerações finais}

Tendo por base o estudo realizado, percebe-se que alguns direcionamentos podem ser visualizados diante da luta das comunidades tradicionais, em todo o país, em ver reconhecido seus direitos, principalmente os da territorialidade, e os delineamentos jurídicos apresentados.

Nas palavras de Boaventura Sousa Santos, existe um processo de reconhecimento de novos direitos que vem sendo garantidos, em sistemas jurídicos constitucionais, antes fechados ao reconhecimento da pluriculturalidade e multietnicidade, foram reconhecendo um a um (...) uma variada formação étnica e cultural. (2003)

Não há como concluir este artigo sem se reportar ao julgamento da Terra Indigena Raposa Serra do Sol (Roraima) pelo STF, norteador de outros casos de sobreposição em razão das dezenove diretrizes editadas naquela oportunidade (Damas, 2010). Pois neste, com menor repercussão na mídia, por se 
tratar de populações menores, mais invisíveis às proteções do Estado e sem o reconhecimento dos indígenas, também padece da mesma problemática, a sobreposição territorial em terras da União.

Aqui os envolvidos (agentes da União e comunidades), tiveram por mérito estudar o conflito, as dimensões de ambos os lado, os interesses conflitantes, fazer esforços de hermenêutica pelo viés da norma constitucional, sopesar ponderar, até chegar a solução que beneficie a ambos e faça justiça social - foi adotado no estudo o método do principio da ponderação.

A discussão enfrentada, as reivindicações dos ribeirinhos em ter demarcado o seu território e titulação deste, bem como os anseios do exercito brasileiro em exercer sua função constitucional com a preservação do meio ambiente e manter a soberania da nação, com legislação analisada, neste estudo permitem concluir que o direito agrário na Amazônia pode e deve valer-se desse arcabouço normativo citado para o fim de adequar-se à realidade amazônica uma vez que pensado, muitas vezes, em descompasso com realidade a que deva aplicar-se, o que compele o teórico e o prático do direito na Amazônia a abandonar a visão positivista e passar a uma compreensão plural (multicultural) do problema jurídico e das demandas por regulação normativa eficiente.

Percebe-se que na solução do conflito, ocorreram negociações intermediadas por autoridades competentes, com a indicação da CDRU, onde há a preocupação com a dignidade humana, em respeitar direitos fundamentais de ambos os lado, e a adoção de princípios como o da proporcionalidade e da ponderação compatibilizando interesses ligados ao meio ambiente, territorialidade dos ribeirinhos e defesa nacional. Nas sábias palavras de Edson Damas da Silveira:

Interpretar o direito em solo amazônico requer uma grande dose de inteligência e boa vontade com o futuro da humanidade. (Silveira, 2010). 
Interessante ressaltar que a concessão da CDRU, embora seja um documento antigo, neste caso destaca-se o seu caráter inovador, quando aplicada em comunidades tradicionais, sendo pioneira no Brasil.(Relatório 12ª RM, 2012)

Assim, embora o direito de ambos venha a ser relativizado, percebe-se que a convivência do atores pode ser harmônica e proveitosa para todos, onde as forças Armadas podem contribuir para a defesa das comunidades ante possíveis invasões e ou agressões externas, implicando essa convivência no respeito aos seus costumes e tradições. Da mesma forma que estas entendam e respeitem suas limitações e atividades próprias do exército, aceitando certas limitações.

Importante ainda asseverar que os interesses no que tange à conservação do meio ambiente são semelhantes. A sustentabilidade ambiental dos povos e comunidades tradicionais tem direta relação com o respeito a direitos $\mathrm{e}$ territórios.

\section{Referencias}

ALEXY, Robert. Constitucionalismo Discursivo. Tradutor: Luís Afonso Heck. Porto Alegre: Livraria do Advogado, 2007.

BARROSO, Luís Roberto. Curso de Direito Constitucional Contemporâneo: os conceitos fundamentais e a construção do novo modelo. São Paulo: Saraiva, 2009.

BARCELLOS, Ana Paula de. Alguns parâmetros normativos para a ponderação constitucional, $3^{\mathrm{a}}$ edição. Rio de Janeiro: Renovar, 2008,

BARROSO, Luís Roberto. A nova interpretação constitucional (Ponderação, Direitos Fundamentais e Relações Privadas). $3^{\text {a }}$ edição. Rio de Janeiro: Renovar, 2008, p. 22.

BRASIL. Constituição Federal, 1988.

BRASIL. Decreto Federal $n^{\circ}$ 6.040, de 7 de fevereiro de 2007. Institui a Política Nacional de Desenvolvimento Sustentável dos Povos e Comunidades tradicionais.

BRASIL. Procedimento Administrativo do MPF n²004-29 \2010.

CARVAlHO, Joana de Moraes Souza Machado de. Colisão de Direitos Fundamentais. Porto Alegre: Sergio Antonio Fabris Ed., 2009. 
DIEGUES, Antonio Carlos. O Mito da Natureza Intocada. São Paulo: Hucitec, 1998.

FRAXE, Therezinha de Jesus Pinto; PEREIRA, Henrique dos Santos; WITKOSKI Antônio Carlos. Comunidades ribeirinhas amazônicas: modos de vida e uso dos recursos naturais. Manaus: EDUA, 2007.

FRAXE, T. J.P. 2011. Homens Anfíbios: etnografia de um campesinato das águas. São Paulo: ANNABLUME.

FREIRE, Paulo. Pedagogia do Oprimido. Rio de Janeiro: Paz e Terra, 1988.

FREITAS, Juarez de. Tendências atuais e perspectivas da hermenêutica constitucional. Ajuris $76 / 397$.

LANE, Renata. (2004), O entendimento do STF em alguns casos de colisão de direitos fundamentais. Monografia de conclusão de curso da Escola de Formação. Sociedade Brasileira de Direito Público, São Paulo, 2004.

LÈNA, Philippe Marie. Dinâmicas socioculturais na Amazônia: identidades, territorialidades e relações interétnicas. - MPEG.

HILÉIA, revista de direito ambiental da Amazônia. An0- 6, nº 11-12-13- jul-dez $\backslash 2008$.

HILÉIA, revista de direito ambiental da Amazônia. ANO 7-8, No 13-14- JUL -DEZ \ 2009.

LOPES, Lorena Duarte Santos. COLISÃO de direitos fundamentais: visão do Supremo Tribunal Federal. Ambito jurídico.com.br. o portal jurídico na internet.

MARMELSTEIN, George. Curso de Direitos Fundamentais. São Paulo: Atlas, 2008.

MORAES, Alexandre de. Direitos humanos fundamentais. 7 ed. São Paulo: atlas, 2006.

MORAN, E. F. A Ecologia Humana das Populações da Amazônia. Petrópolis, RJ: Vozes. 1990.

RELATÓRIO da Iniciativa CDRU- 12ª Região Militar, 2013

SANTILLI, Juliana. Socioambientalismo e novos direitos: protę̧ão jurídica à diversidade biológica e cultural. ed Peirópolis, 2005.

SARLET, Ingo Wolfgang. A eficácia dos direitos fundamentais. $6^{\mathrm{a}}$ ed., Porto Alegre: Livraria do Advogado, 2006.

SARMENTO, Daniel. A ponderação de Interesses na Constituição Federal. 1. ed. Rio de Janeiro: Lumen Júris, 2002.

SARMENTO, Daniel. GALDINO, Flávio. Direitos Fundamentais: estudos em homenagem ao professor Ricardo Lobo Torres. Rio de Janeiro: Renovar, 2006. 
SILVEIRA, Edson Damas da. Meio ambiente, terras indígenas e defesa nacional: direitos fundamentais em tensão nas fronteiras da Amazônia Brasileira. Curitiba: Juruá, 2010.

WITKOSKI Antônio Carlos. Terras, florestas e águas de trabalho: os camponeses amazônicos e as formas de usos de seus recursos naturais. Editora Universidade Federal do Amazonas. 2010.

WOLKMER, Antonio Carlos. Constitucionalismo e direitos sociais no Brasil. São Paulo. Acadêmica. 2005. 